\title{
Review of The end of value-free economics, edited by Hilary Putnam and Vivian Walsh. Routledge, 2011, 230pp.
}

\section{DANIEL LITTLE}

University of Michigan-Dearborn

This recent volume edited by Vivian Walsh and Hilary Putnam, collating contributions to a debate in the pages of the Review of Political Economy between 2000 and 2009, brings to a fine point a line of argument that has been brewing for fifteen years: is the logical positivist insistence on separating "fact-based" science from "value-based" ethics any longer tenable? Most particularly, are there now compelling reasons for declaring that mainstream economics needs to recognize that the distinction is wholly untenable? Is the zeal for insisting on "positive" economics now unsupportable? Should economists at last recognize that Lionel Robbins's strong exclusion of normative language from the science of economics (1932) was both unjustified and unwise? Walsh and Putnam argue that the answer to each of these questions is definitive: the strict dichotomy between fact and value in economics can no longer be supported.

The contemporary issue of facts and values in the sciences was constructed from a number of sources within the empiricist tradition. There is Hume's claim that we cannot derive "ought" from "is"; or, in other words, that moral judgments are logically independent from empirical beliefs. There is the positivists' criterion of significance, according to which the meaning of an utterance reduces to the empirical experiences that would demonstrate its truth or falsity. (The two propositions together imply that moral sentences are meaningless or "non-cognitive", since the first proposition holds that no empirical experience can demonstrate the truth or falsity of a normative statement.) And there is the positivists' view that science is exclusively concerned with "facts"; and, since the first two propositions consign moral statements to the category of "value" rather than "fact", therefore science cannot contain normative vocabulary. Another source was internal to debates within neoclassical economics itself: Lionel Robbins's arguments against interpersonal comparisons of utilities, based on the 
idea that making such comparisons unavoidably involves taking an evaluative stance towards the individuals in question (Robbins 1932).

The key idea advanced in The end of value-free economics is that none of these philosophical ideas have survived the critique of positivism offered within philosophy of science and philosophy of language over the past fifty years. The attempt to draw a sharp line between "fact" and "value" turns out to be impossible. And this is equally so in economics.

Consider an example. The concept of Pareto efficiency is defined in value-neutral terms: a distribution is Pareto-efficient if there is no other distribution that benefits some individuals without harming at least one individual. Whether or not a distribution is Pareto-efficient can be determined without making any ethical or value-based judgments. (There is, to be sure, a corresponding normative principle: "If a distribution is Pareto-efficient then it is unjust to alter the distribution". This principle is indeed value laden, but it is not part of the economic concept of Pareto efficiency.) The concept of distributive justice is not value-neutral; it invokes the idea that some distributions are better because they are fairer or more just than others. The positive economist holds that such distinctions are legitimate to make-in some other arena. But within economics the language of justice and equity has no place. The economist, according to this view, can work out the technical characteristics of various economic arrangements; but it is up to the political process or the policy decision-maker to arrive at a governing set of normative standards. Walsh and Putnam (as well as Amartya Sen) dispute this view on logical grounds; and thereby show that the discipline is free to have a rational and reasoned discussion of the pros and cons of various principles of distributive justice.

Raising the issue of value-neutrality for economics is a frontal assault on the uncritical positivism that neoclassical economics incorporated from the 1930s onwards. But it is also an attack on something else-the no-longer acceptable idea that economists can only tell us how things are, not how they should be. Is famine worse than food sufficiency? Is literacy better than illiteracy? Is good health an improvement in wellbeing? If we take the view that "positive economics" cannot contain normative judgments, then none of these questions could be answered by an economist. "It depends on what you value". What Walsh, Putnam, Sen, and other contributors to this volume want to say is that this response is idiotic, and there is no basis in logic, 
science, or methodology that would support it. Of course economics, and economists, can find that starvation is a bad thing. Instead, they maintain that the best philosophy of language and philosophy of science supports the idea that value concepts and descriptive concepts are intermingled or "entangled", and that we can offer good reasons and evidence for evaluating claims involving both.

Why, some readers will ask, has Hilary Putnam become a central figure in this emerging debate? Putnam is known as a technically astute philosopher of mathematics, logic, and physics, and a philosopher of language; he is known for a sometimes wavering adherence to several versions of scientific realism; and he has made contributions of the greatest importance to each of these fields. But how did he come to get deeply immersed in the issue of the role of values in economics?

Vivian Walsh is one important part of the answer. Walsh undertook a series of publications in the 1980s and 1990s that were critical of the logical positivist assumptions that have lingered within the methodology of neoclassical economics (Walsh 1987; 1994; 1996). He took encouragement from the writings of Amartya Sen on welfare economics that confidently dismissed these positivist assumptions-for example, the idea that science could not incorporate values or that statements about values were meaningless. (Lionel Robbins was offered as a particularly clear advocate of these views.) And Putnam after reading Walsh's (2000) reconsideration of Adam Smith worked up his reactions to these ideas into a novel book in 2002, The collapse of the fact/value dichotomy and other essays (Putnam 2002).

A key construct in the collaborative thinking that Putnam and Walsh have done together is the idea of the "second phase of classical theory". (Harvey Gram discusses this construction in detail in his contribution.) Walsh introduces the idea and Putnam follows up in his essay. What this refers to is the fact that classical political economy, as founded by Smith and Ricardo, underwent a major intellectual revival in the 1960s when thinkers like Piero Sraffa proposed reappropriating some of their key analytical ideas. Sraffa's Production of commodities by means of commodities: prelude to a critique of economic theory (1960) was a key product of this rethinking. The rethinking itself came about because of an uneasiness about the premises of neoclassical economics. According to Walsh, this phase restricted itself to providing a rigorous reformulating of the technical core of classical economics rather than reintroducing the broader context of argument offered by Adam Smith. 
The first phase of the revival focused on Ricardo, but the second phase, Walsh argues, has given a much more nuanced interpretation of Smith himself. Walsh finds that this reconsideration has been led by Amartya Sen and is more wide-ranging. Here is why Walsh thinks this reconsideration of Smith is important:

This is because Smith embedded a remarkable understanding of the core concepts of a political economy whose implications for moral philosophy he understood and explored. The Smith texts as a whole offer a rich tapestry, interweaving threads of classical analysis, moral philosophy, jurisprudence, and history (p. 7).

And here is how Putnam summarizes Sen's contribution to this reconsideration of classical political economy:

If we are to understand Sen's place in history, the reintroduction of ethical concerns and concepts into economic discourse must not be thought of as an abandonment of "classical economics"; rather it is a reintroduction of something that was everywhere present in the writings of Adam Smith, and that went hand-in-hand with Smith's technical analyses. This is something that Sen himself stresses (quoted by Walsh, 29).

Amartya Sen has argued robustly throughout his career for the feasibility of philosophical and analytical reasoning about value issuesin economics and elsewhere-a very early place where Sen takes up this topic is in "The nature and classes of prescriptive judgements" (1967). Much of what Sen brings to this debate within economics, according to Walsh and Putnam, is found in his capability approach as a foundation for a theory of welfare or wellbeing. It is based on the idea of human 'functionings' (what people can be and do), in which there is a plain intermingling of factual and evaluative ideas. We need to know what kind of lives people can lead before we can say how well off they are. And this means bringing human values into the discussion of economics at the beginning rather than at the end. Putnam draws attention to Martha Nussbaum's list of central human capabilities (Nussbaum 2000). Anyone reading Nussbaum's descriptions would agree that they presuppose human values. And Nussbaum (as well as Sen and Putnam) believes that we can rationally discuss and evaluate these. But if welfare economics is to incorporate a substantive notion of human wellbeing, then it plainly cannot be maintained that it is "value-free". 
Another important locus for Sen's reintroduction of ethical concepts into economics is his critique of the narrow conception of individual economic rationality. As Sen puts the point in "Rational fools" (1977):

A person thus described may be "rational" in the limited sense of revealing no inconsistencies in his choice behavior, but if he has no use for these distinctions between quite different concepts, he must be a bit of a fool. The purely economic man is indeed close to being a social moron. Economic theory has been much preoccupied with this rational fool decked in the glory of his one all-purpose preference ordering. To make room for the different concepts related to his behavior we need a more elaborate structure (p. 336).

Sen introduces the idea of "commitments" directly into the concept of economic rationality. Individuals choose among preference rankings based on their commitments-to each other, to political ideas, to groups with whom they have decided to affiliate. And this brings normative ideas directly into economic reasoning at the level of the actor-and therefore into the domain of economics.

Walsh and Putnam insist on a point that seems very important to me as well: it is the dichotomy based on strict separability between facts and values, or between positive and normative analysis, that they reject. They do not reject the idea that there are facts and there are values. But they believe in important respects these categories are intertwined and inseparable. They argue for "entanglement" and "rich description". So we can distinguish between value aspects and factual aspects of a situation; but we cannot strictly separate these aspects in our reasoning about the situation. Putnam writes in his contribution to the volume, "I try to show that value judgment and factual judgment are entangled in many ways, not just one. But one of the most important ways is this: there are facts $[\ldots]$ which only come into view through the lenses of an evaluative outlook" (p. 112). Both Putnam and Walsh believe that it is fully possible and acceptable to engage in rational debates over the best theory of justice, or human nature, or human freedom; and to do so within economics as well as outside of economics. And they believe that science can pursue its goals without this sharp dichotomy.

This is a valuable contribution, offering the most sustained presentation to date of the reasons why the fact-value dichotomy cannot stand as a criterion of adequacy of the science of economics. It is a stimulating and rigorous conversation among a set of highly gifted philosophers and economists who have engaged deeply with the 
underlying issues in the philosophy of science and the philosophy of economics. Anyone who wants to see the development of a discipline of economics that is better able to confront the economic and social challenges of the twenty-first century will certainly want to read it.

\section{REFERENCES}

Nussbaum, Martha. 2000. Women and human development: the capabilities approach. Cambridge: Cambridge University Press.

Putnam, Hilary. 2002. The collapse of the fact/value dichotomy and other essays. Cambridge: Harvard University Press.

Robbins, Lionel. 1932. An essay on the nature and significance of economic science. London: MacMillan.

Sen, Amartya. 1967. The nature and classes of prescriptive judgements. The Philosophical Quarterly, 17 (66): 46-62.

Sen, Amartya. 1977. Rational fools: a critique of the behavioral foundations of economic theory. Philosophy and Public Affairs, 6 (4): 317-344.

Sraffa, Piero. 1960. Production of commodities by means of commodities: prelude to a critique of economic theory. Cambridge: Cambridge University Press.

Walsh, Vivian. 1987. Philosophy and economics. In The New Palgrave: a dictionary of economics, eds. John Eatwell, Murray Milgate, and Peter Newman. London: Macmillan, 861-869.

Walsh, Vivian. 1994. Rationality as self-interest versus rationality as present aims. American Economic Review, 84 (2): 401-405.

Walsh, Vivian. 1996. Rationality, allocation, and reproduction. Oxford: Oxford University Press.

Walsh, Vivian. Smith after Sen. Review of Political Economy, 12 (1): 5-25.

Daniel Little is professor of philosophy and chancellor of the University of Michigan-Dearborn. His research interests concern the philosophy and methodology of the social sciences. His most recent books include The future of diversity (Palgrave, 2010; edited with Satya Mohanty) and New contributions to the philosophy of history (Springer, 2010). He publishes a web based monograph, Understanding society, on the philosophy of social science and the nature of the social world.

Contact e-mail: <delittle@umd.umich.edu>

Blog: <http://understandingsociety.blogspot.com/> 